\title{
Dietary Habits and Oral Hygiene Practice amongst Dental Students at the College of Dentistry, Princess Nourah University
}

\author{
Ebtissam M. Al-Madi1,2, Manar AlJamieํ, Shaikha Al-Dukhail1', Zakariya Mohammed³, \\ Neamat Hassan Abubakr ${ }^{1 * \#}$ \\ ${ }^{1}$ College of Dentistry, Princess Nourah bint Abdulrahman University, Riyadh, Kingdom of Saudi Arabia \\ ${ }^{2}$ College of Dentistry, King Saud University, Riyadh, Kingdom of Saudi Arabia \\ ${ }^{3}$ Faculty of Science, Northern Border University, Arar, Kingdom of Saudi Arabia \\ Email: emalmadi@pnu.edu.sa,manaraljamie@hotmail.com,skaldukhail@pnu.edu.sa, \\ zakariya.mohammed@gmail.com, "nhabubakr@pnu.edu.sa, "neamat@yahoo.com
}

Received 12 December 2015; accepted 19 January 2016; published 22 January 2016

Copyright (C) 2016 by authors and Scientific Research Publishing Inc.

This work is licensed under the Creative Commons Attribution International License (CC BY).

http://creativecommons.org/licenses/by/4.0/

(c) (i) Open Access

\begin{abstract}
The aim of the present study was to assess the dietary habits and oral hygiene practice of dental students in a new dental school. A self-administered structured closed-ended questionnaire on demographic characteristics, medical history, oral hygiene and dietary habits was distributed to dental students. Results showed that One third of students indicated that they don't consume low pH beverages (soft drinks) at all, while $48.9 \%$ drink a soft drink or two a day. Students took varying amount of time to consume their drinks. The majority of participants consumed citric juices, fruits and/or pickles at least once a day. $91.3 \%$ of students use either soft $(41.8 \%)$ or medium (49.5\%) toothbrush. Only a fifth (16.9\%) of the students brush their teeth after drinking soft drinks and $58.2 \%$ brush their teeth after vomiting. In conclusion, young adults need to be aware about their dietary habits \& oral hygiene, and also a proper dental health program needs to be applied.
\end{abstract}

\section{Keywords}

Dietary Habits, Oral Hygiene Practice, Low pH Soft Drinks

\section{Introduction}

Diet has a direct and local effect on oral health, especially on the $\mathrm{pH}$ and composition of saliva, plaque and the

${ }^{*}$ Corresponding author.

"Professor Neamat Hassan Abubakr, BDS, DSS (Austria), MDSc (Scotland), PhD (Japan), Vice Dean For Research \& Postgraduate Studies, College of Dentistry, Princess Nourah bint Abdelrahman University.

How to cite this paper: Al-Madi, E.M., AlJamie, M., Al-Dukhail, S., Mohammed, Z. and Abubakr, N.H. (2016) Dietary Habits and Oral Hygiene Practice amongst Dental Students at the College of Dentistry, Princess Nourah University. Open Journal of Stomatology, 6, 28-35. http://dx.doi.org/10.4236/ojst.2016.61004 
teeth; it plays a major etiological role in dental caries and dental erosion [1]. Dental erosion is defined as a complex multifactorial condition, characterized by an irreversible loss of dental hard tissue caused by action of chemical influence of extrinsic and intrinsic acids without bacterial involvement [2] [3]. Both incidence and prevalence of dental erosion have increased considerably among children \& young adults [4]-[6]. Lifestyles have changed through time with the high consumption of acidic food \& carbonated beverages [7]. Dietary acids are one of the most commonly cited causes of erosion [8], and soft drink consumption has been associated with dental erosion [9]. Intervention measures should be taken to prevent or reduce dental erosion from diet factors [10]. Many clinical studies have focused only on schoolchildren, since it is easier to recruit them in trials compared with adults. However, it is important to record erosive wear in all age groups to gather comprehensive information about the prevalence, distribution and incidence of erosive wear among different ages with possible different dietary habits [11] [12]. Geographic location seems to influence the prevalence rates observed in literature, since cultural, ethnical and dietary habits vary according to the region where the study was conducted [13] [14]. Saudi Arabia is one of several countries who underwent an especially rapid development and modernization with food culture changes in the past decades, through adoption of a more westernized diet in lifestyle. These food culture changes are likely to have an effect on oral health among all age classes. The consumption of acidic foods on a daily basis elevates the risks of erosive tooth wear with age advancement. Nevertheless, there has been little consideration of erosive tooth wear in particularly Asian countries; a recent single research (2015) was conducted in Japan to evaluate the association between erosive wear and acidic habits showed that frequent consumption of acidic fruits and drinks was significantly associated with erosive tooth wear at different age groups [15].

Oral health providers are often the first health care professional in primary, secondary and tertiary prevention of oral/systemic health issues [16]. These roles in prevention require the acquisition of numerous cross-disciplinary psychosocial and skill-based competencies ranging from role beliefs and commitment, to collaborative care [16] [17]. A long-standing challenge in dental education is preparing future clinicians to participate in prevention of oral/systemic health issues [14]-[18].

Dental students learn about oral hygiene habits, dietary counseling and dental erosion early on in their dental studies for the purpose of educating their patients about the effect of diet on oral health. As they learn more about the effects of diet and oral hygiene habits, they should internalize and develop good dietary and oral hygiene habits in order to be good role models for their patients. However, knowledge and awareness do not always produce positive behaviors.

The aim of the present study was to assess the dietary habits and oral hygiene practice of dental students in a new dental school.

\section{Material \& Methods}

The research \& ethics committee of the College of Dentistry, Princess Nourah bint Abdelrahman University, approved the study (Registered No. 2015/CDS/RD/001). A questionnaire survey was conducted among dental students of College of Dentistry, Princess Nourah University (PNUCD). A self-administered structured closedended questionnaire on demographic characteristics, oral hygiene and dietary habits was partial adapted from Chu et al was distributed [19]. The questionnaire composed of two sections; first section inquired about the oral hygiene practice $(\mathrm{OH})$ the second section asked about their dietary habits $(\mathrm{DH})$ (Table 1). The questionnaire was distributed to all students of the college of dentistry, Princess Nourah bint Abdelrahman University. The data was collected and analyzed by using the Statistical Package for the Social Sciences (IBM SPSS STATISTICS 22, IBM Corporation, USA, 2013) was used for all data analysis. Fisher exact test was used to examine presence of statistically significant association (Figure 1).

\section{Results}

A total of 96 dental students completed the self-administered structured closed-ended questionnaire giving a response rate of $82.1 \%$. The 96 enrolled students were as follows; 31 students from grade 3 (which is the senior class); 33 students from grade 2 while 32 students participated from grade 1 . The average age of the students is 18 years ( $\mathrm{SD} \pm 0.9$ years).

The majority of the dental students (91.3\%) used either soft (41.8\%) or medium (49.5\%) toothbrush. Normal toothpaste was used by $51.1 \%$ of the participants while $30 \%$ were using whitening toothpaste and only $10 \%$ use 
Table 1. Oral hygiene practice.

\begin{tabular}{|c|c|c|}
\hline \multirow{5}{*}{ What type of toothbrush do you use? } & Soft & $41.8 \%$ \\
\hline & Medium & $49.5 \%$ \\
\hline & Hard & $2.2 \%$ \\
\hline & Don't know & $6.5 \%$ \\
\hline & Total & $100.0 \%$ \\
\hline & Whitening & $30.0 \%$ \\
\hline & High-strength Fluoridated & $10.0 \%$ \\
\hline What type of toothpaste do you usually use? & Normal & $51.1 \%$ \\
\hline & Don't know & $8.9 \%$ \\
\hline & Total & $100.0 \%$ \\
\hline & Yes & $16.9 \%$ \\
\hline After drinking soft drinks do you brush your teeth? & No & $83.1 \%$ \\
\hline & Total & $100.0 \%$ \\
\hline & Yes & $58.2 \%$ \\
\hline Do you brush your teeth after vomiting? & No & $41.8 \%$ \\
\hline & Total & $100.0 \%$ \\
\hline Q1. Questionnaire No: & Age in years & Grade: \\
\hline$-\longrightarrow-$ & - & - \\
\hline ORAL HYGIENE & & OH \\
\hline $\mathrm{OH}$ 1. What type of tooth brush do you Use? & Medium & $\begin{array}{l}1 \\
2 \\
3 \\
4\end{array}$ \\
\hline $\mathrm{OH} 2$. What type of tooth paste do you usually use? & 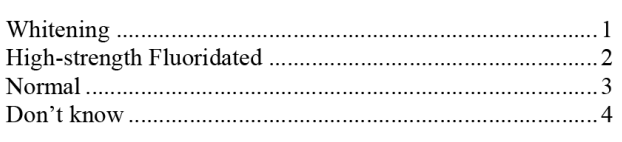 & $\begin{array}{l}1 \\
2 \\
3 \\
4\end{array}$ \\
\hline OH. 3. After drinking soft drinks do you brush your teeth? & Yes & 1 \\
\hline OH 4. Do you brush your teeth after vomiting? & Yes No & \\
\hline DIET HABIT & & DH \\
\hline $\begin{array}{l}\text { OH 1. In a day, how often on average do you drink low } \\
\text { pH soft drinks beverages (i.e. Pepsi, Coca-Cola, sport } \\
\text { drinks) Please include the frequency in between your } \\
\text { breakfast and lunch, lunch and dinner, and after dinner } \\
\text { until you go to bed? }\end{array}$ & 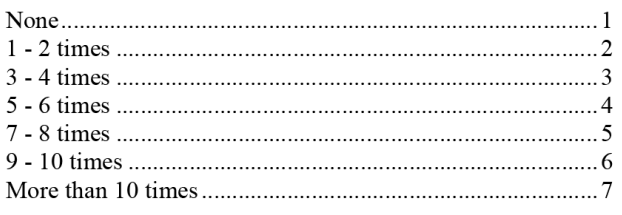 & $\begin{array}{l}\text { If None } \\
\Rightarrow \mathrm{OH} 3\end{array}$ \\
\hline $\mathrm{OH} 2$. Length of time taken to consume drink & $\begin{array}{l}\text { Immediately } \\
1 \text { - } 5 \text { minutes } \\
6 \text { - } 10 \text { minutes } \\
11 \text { - } 15 \text { minutes } \\
\text { Above } 15 \text { minutes }\end{array}$ & \\
\hline $\begin{array}{l}\text { OH. } 3 \text {. In a day, how often on average do do you take } \\
\text { any one of these citrus juices, Orange, Grape fruit, } \\
\text { yoghurt and pickled. }\end{array}$ & 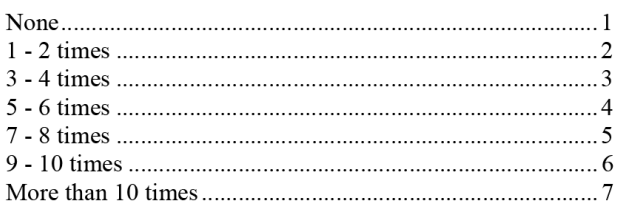 & \\
\hline
\end{tabular}

Figure 1. Dietary behavior among dental students at PNU questionnaire. 
high strength fluoridated toothpaste. Only $16.9 \%$ of students brush their teeth after consuming soft drinks and $58.2 \%$ brush their teeth after vomiting (Table 1 ).

One third of students indicated that they don't consume low $\mathrm{pH}$ beverages (soft drinks) at all, while 48.9\% drink a soft drink or two a day. Students took varying amount of time to consume their drinks. The majority of participants consumed citric juices, fruits and/or pickles at least once a day (Table 2).

The type of toothbrush and toothpaste, the participants used were associated significantly with students level (Table 3).

\section{Discussion}

The increase in the population of the Kingdom, along with an awareness of people about the importance of dental care, opened the option for the establishment of more dental schools. Right now the Kingdom of Saudi Arabia has almost 24 dental colleges distributed all over the Kingdom. The participants were students of a new dental College in Saudi Arabia and the first and only college for female students in the largest female university in the world.

Dental erosion is becoming increasingly prevalent especially among young generations and its damaging effect is emerging as a serious public health issue. In the present study, more than half of the participants brush their teeth after vomiting. Moreover, tooth-brushing frequency has been associated with dental erosion in some studies [20] [21] while other reports have not verified this conclusion [22] [23].

Dietary factors, particularly acidic food and drinks, contribute to the development of dental erosion [24]-[26]. If measures are not taken to prevent the loss of dental tissue there are no doubt that excessive erosive tooth surface loss can lead to complications such as pain, dentin hypersensitivity or even pulpal inflammation which might lead to loss teeth. It is not only students knowledge that is important to prevent this phenomenon, but actual dietary and oral hygiene habits based on this knowledge, In the present study, most of students indicated

Table 2. Dietary habits of the dental students.

\begin{tabular}{|c|c|c|}
\hline Question & Frequency & Percentage (\%) \\
\hline \multirow{8}{*}{$\begin{array}{l}\text { In a day, how often on average do you drink low pH soft drinks } \\
\text { beverages }\end{array}$} & None & $33.0 \%$ \\
\hline & $1-2$ times & $48.9 \%$ \\
\hline & 3 - 4 times & $12.8 \%$ \\
\hline & 5 - 6 times & $4.3 \%$ \\
\hline & 7 - 8 times & $0.0 \%$ \\
\hline & 9 - 10 times & $1.0 \%$ \\
\hline & More than 10 times & $0.0 \%$ \\
\hline & Total & $100.0 \%$ \\
\hline \multirow{6}{*}{ Length of time taken to consume drink (in minutes) } & Immediately & $7.1 \%$ \\
\hline & 1 - 5 minutes & $27.1 \%$ \\
\hline & 6 - 10 minutes & $28.6 \%$ \\
\hline & 11 - 15 minutes & $14.3 \%$ \\
\hline & Above 15 minutes & $22.9 \%$ \\
\hline & Total & $100.0 \%$ \\
\hline \multirow{8}{*}{$\begin{array}{l}\text { In a day, how often on average do you take any one of these citrus } \\
\text { juices, Orange, Grape fruit, yoghurt and pickles (frequency). }\end{array}$} & None & $17.2 \%$ \\
\hline & 1 - 2 times & $67.7 \%$ \\
\hline & 3 - 4 times & $14.0 \%$ \\
\hline & $5-6$ times & $1.1 \%$ \\
\hline & 7 - 8 times & $0.0 \%$ \\
\hline & 9 - 10 times & $0.0 \%$ \\
\hline & More than 10 times & $0.0 \%$ \\
\hline & Total & $100.0 \%$ \\
\hline
\end{tabular}


Table 3. Association between selected practices and student grade.

\begin{tabular}{|c|c|c|c|c|c|}
\hline \multirow{2}{*}{ Question } & \multirow{2}{*}{ Responses } & \multicolumn{3}{|c|}{ Level } & \multirow{2}{*}{ P Value } \\
\hline & & D1 & D2 & D3 & \\
\hline \multirow{5}{*}{ What type of toothbrush do you use? } & Soft & $34.5 \%$ & $18.2 \%$ & $75.9 \%$ & \multirow{5}{*}{$0.000^{*}$} \\
\hline & Medium & $55.2 \%$ & $66.7 \%$ & $24.1 \%$ & \\
\hline & Hard & $0.0 \%$ & $6.1 \%$ & $0.0 \%$ & \\
\hline & Don’t know & $10.3 \%$ & $9.1 \%$ & $0.0 \%$ & \\
\hline & Total & $100.0 \%$ & $100.0 \%$ & $100.0 \%$ & \\
\hline \multirow{5}{*}{ What type of toothpaste do you usually use? } & Whitening & $30.0 \%$ & $36.4 \%$ & $22.2 \%$ & \multirow{5}{*}{$0.040^{*}$} \\
\hline & High-strength Fluoridated & $0.0 \%$ & $9.1 \%$ & $22.2 \%$ & \\
\hline & Normal & $56.7 \%$ & $42.4 \%$ & $55.6 \%$ & \\
\hline & Don’t know & $13.3 \%$ & $12.1 \%$ & $0.0 \%$ & \\
\hline & Total & $100.0 \%$ & $100.0 \%$ & $100.0 \%$ & \\
\hline \multirow{3}{*}{$\begin{array}{l}\text { After drinking soft drinks do you brush your } \\
\text { teeth? }\end{array}$} & Yes & $20.7 \%$ & $15.6 \%$ & $14.3 \%$ & \multirow{3}{*}{0.825} \\
\hline & No & $79.3 \%$ & $84.4 \%$ & $85.7 \%$ & \\
\hline & Total & $100.0 \%$ & $100.0 \%$ & $100.0 \%$ & \\
\hline \multirow{3}{*}{ Do you brush your teeth after vomiting? } & Yes & $71.4 \%$ & $57.6 \%$ & $46.7 \%$ & \multirow{3}{*}{0.162} \\
\hline & No & $28.6 \%$ & $42.4 \%$ & $53.3 \%$ & \\
\hline & Total & $100.0 \%$ & $100.0 \%$ & $100.0 \%$ & \\
\hline
\end{tabular}

that they drink low pH soft drinks at least once a day, even though they should be knowledgeable of the detrimental effect these acidic drinks have on their teeth. The development of dental erosion had shown a significant association with the consumption of low pH soft drinks and fruit juices [27]-[29].

In the present study, more than one third of the participants (37.3\%) consume low $\mathrm{pH}$ drinks for more than 10 minutes. The frequency and time the teeth are in contact with the acidic beverage and maybe an important behavioral factor contributing to the development of dental erosion [29] [30]. It has been suggested that retaining the drink in the mouth, prior to swallowing, causes a greater $\mathrm{pH}$ drop at the tooth surfaces compared to swallowing it immediately [30]-[32].

Different research groups have pointed out sour sweets as a new type of erosive challenge [33]. A very recent study showed that not only the $\mathrm{pH}$ of the drinks but also the high intake of sour sweets could increase the risk of dental erosive wear [34].

Due to the very acidic $\mathrm{pH}$ and prolonged oral contact, sour sweets could represent a high risk of damage to the dentition [35] [36]. It is also an interesting observation that the Food Standards Agency issued a warning of its damaging effects to the oral mucosa due to its acidic $\mathrm{pH}$ (21-Food standards agency 2014). Although not widely documented regarding dental erosive wear, sour sweets have been suggested to be a contributor too important to disregard [35] [36]. Some researchers have not found a relationship between dental erosion and fruit and acidic drinks [37] [38]. There was growing evidence in the UK, that a major cause of tooth erosion is gastroesophageal reflux, [39]. In addition, a large proportion of people with anorexia and bulimia nervosa develop dental erosion from repeated vomiting [40]. Before appropriate public education programs can be designed, prevalence data are needed to understand the scope of the problem for different countries, different age groups, and different conditions or diets. There was a clear association between selected oral hygiene practice and student level, higher level student were aware about the oral hygiene practice more the first grade students. In order to provide patients with a proper oral health care, young adults must be aware of all issues involved in dental erosion through dental health education which will essential help in the understand dental erosion and its damaging effects.

Low pH Soft drinks can cause damage to the teeth for two reasons: Firstly, the high acidity due to the low pH. Secondly the generated organic acids that brings about demineralization. Dental Erosion is usually due to the loss of the outermost surface of enamel and occurs when the surface $\mathrm{pH}$ falls below 5.5 [31]. Low $\mathrm{pH}$ together with low calcium and fluoride ion concentration indicate the high erosive potential [32]. A meta-analysis study conducted 2012 by Li et al. showed that erosions are mainly caused by excessive consumption of erosive food 
and drinks especially among children [10].

With regard to prevention of eating disorders, studies have found that training oral health professionals in such practices as assessment, patient approach/communication, behavior change strategies, and referral resources is lacking in their educational preparation [41] [42]. In recent years there have been several suggestions aimed at improving dental training in regards to knowledge of oral/systemic topics, higher order thinking skills, attitudes, interpersonal skills, personal values, and multidisciplinary training [43]-[45]. Despite growing literature and a call for dental education reform in 2010 [46], dental educators had just recently begun advocating for education reform [44]. Nonetheless, there is still a lack of standardized, comprehensive curriculum regarding disordered eating behaviors and communication/interpersonal skills. Dental students should be more aware and knowledgeable about the outcome of the effects of diet and oral hygiene habits since this will be one of their main tasks as oral health providers. The limitation of the present study was the small number of participants also other dietary habits such as snacks and sweets intake needed to be more investigated.

\section{Conclusion}

Internalizing the dietary habits associated with good oral care will definitely influence the motivation of students to propagate oral health education for their patients in the future.

\section{Acknowledgements}

Special thanks are extended to dental students of the College of Dentistry, Princess Nourah bint Abdulrahman University.

\section{Competing Interests}

The authors declare that they have no competing interests.

\section{References}

[1] König, K.G. (2000) Diet and Oral Health. International Dental Journal, 50, 162-174. http://dx.doi.org/10.1111/j.1875-595X.2000.tb00555.x

[2] Young, A., Amaechi, B.T., Dugmore, C., Holbrook, P., Nunn, J.H. and Schiffner, U. (2008) Current Erosion Indices Flawed or Valid? Summary. Clinical Oral Investigations, 12, 59-63. http://dx.doi.org/10.1007/s00784-007-0180-6

[3] O’Sullivan, E. and Milosevic, A. (2008) British Society of Paediatric Dentistry. UK National Clinical Guidelines in Paediatric Dentistry: Diagnosis, Prevention and Management of Dental Erosion. International Journal of Paediatric Dentistry, 18, 29-38. http://dx.doi.org/10.1111/j.1365-263X.2008.00936.x

[4] Lussi, A. (2006) Erosive Tooth Wear-A Multifactorial Condition of Growing Concern and Increasing Knowledge. Dental Erosion. Monogr Oral Sci. Basel, Karger, 20, 1-8.

[5] Nunn, J.H., Gordon, P.H., Morris, A.J., Pine, C.M. and Walker, A. (2003) Dental Erosion-Changing Prevalence? A Review of British National Children's Surveys. International Journal of Paediatric Dentistry, 13, 98-105. http://dx.doi.org/10.1046/j.1365-263X.2003.00433.x

[6] Jaeggi, T. and Lussi, A. (2006) Prevalence, Incidence and Distribution of Erosion. Dental Erosion. Monogr Oral Sci. Basel, Karger, 20, 44-65.

[7] Featherstone, J. and Lussi, A. (2006) Understanding the Chemistry of Dental Erosion. Dental Erosion. Monogr Oral Sci. Basel, Karger, 20, 66-76. http://dx.doi.org/10.1159/000093351

[8] Moynihan, P. and Petersen, P.E. (2004) Diet, Nutrition and the Prevention of Dental Diseases. Public Health Nutrition, 7, 201-226. http://dx.doi.org/10.1079/PHN2003589

[9] Touger-Decker, R. and Mobley, C.C. (2003) Position of the American Dietetic Association: Oral Health and Nutrition. Journal of the Academy of Nutrition and Dietetics, 103, 615-625. http://dx.doi.org/10.1053/jada.2003.50130

[10] Li, H., Zou, Y. and Ding, G. (2012) Dietary Factors Associated with Dental Erosion: A Meta-Analysis. PLoS One, 7, e42626. http://dx.doi.org/10.1371/journal.pone.0042626

[11] Lussi, A., Schaffner, M., Hotz, P. and Suter, P. (1991) Dental Erosion in a Population of Swiss Adults. Community Dentistry and Oral Epidemiology, 19, 286-290. http://dx.doi.org/10.1111/j.1600-0528.1991.tb00169.x

[12] Jaeggi, T. and Lussi, A. (2014) Prevalence, Incidence and Distribution of Erosion. Monographs in Oral Science, 25, 55-73. http://dx.doi.org/10.1159/000360973 
[13] Kazoullis, S., Seow, W.K., Holcombe, T., Newman, B. and Ford, D. (2007) Common Dental Conditions Associated With Dental Erosion in Schoolchildren in Australia. Pediatric Dentistry, 29, 33-39.

[14] Wang, P., Lin, H.C., Chen, J.H. and Liang, H.Y. (2010) The Prevalence of Dental Erosion and Associated Risk Factors in 12-13-Year-Old School Children in Southern China. BMC Public Health, 10, 478. http://dx.doi.org/10.1186/1471-2458-10-478

[15] Kitasako, Y., Sasaki, Y., Takagaki, T., Sadr, A. and Tagami, J. (2015) Age-Specific Prevalence of Erosive Tooth Wear by Acidic Diet and Gastroesophageal Reflux in Japan. Journal of Dentistry, 43, 418-423. http://dx.doi.org/10.1016/j.jdent.2015.02.004

[16] Wilder, R.S., O’Donnell, J.A., Barry, J.M., Galli, D.M., Hakim, F.F., Holyfield, L.J. and Robbins, M.R. (2008) Is Dentistry at Risk? A Case for Interprofessional Education. Journal of Dental Education, 72, 1231-1237.

[17] Yoshida, T., Milgrom, P. and Coldwell, S. (2002) How Do U.S. and Canadian Dental Schools Teach Interpersonal Communication Skills? Journal of Dental Education, 66, 1281-1288.

[18] Kassebaum, D., Hendricson, W.D., Taft, T. and Haden, N.K. (2004) The Dental Curriculum at North American Dental Institutions in 2002-03: A Survey of Current Structure, Recent Innovations, and Planned Changes. Journal of Dental Education, 68, 914-931.

[19] Chu, C.H., Pang, K.K. and Lo, E.C. (2010) Dietary Behavior and Knowledge of Dental Erosion among Chinese Adults. BMC Oral Health, 10, 13. http://dx.doi.org/10.1186/1472-6831-10-13

[20] Bardolia, P., Burnside, G., Ashcroft, A., Milosevic, A., Goodfellow, S.A., Rolfe, E.A. and Pine, C.M. (2010) Prevalence and Risk Indicators of Erosion in Thirteen- to Fourteen-Year-Olds on the Isle of Man. Caries Research, 44, 165168. http://dx.doi.org/10.1159/000314067

[21] Mulic, A., Skudutyte-Rysstad, R., Tveit, A.B. and Skaare, A. (2012) Risk Indicators for Dental Erosive Wear among 18-Year-Old Subjects in Oslo, Norway. European Journal of Oral Sciences, 120, 531-538. http://dx.doi.org/10.1111/j.1600-0722.2012.00997.x

[22] Bartlett, D.W., Lussi, A., West, N.X., Bouchard, P., Sanz, M. and Bourgeois, D. (2013) Prevalence of Tooth Wear on Buccal and Lingual Surfaces and Possible Risk Factors in Young European Adults. Journal of Dentistry, 41, 10071013. http://dx.doi.org/10.1016/j.jdent.2013.08.018

[23] El Aidi, H., Bronkhorst, E.M., Huysmans, M.C. and Truin, G.J. (2011) Multifactorial Analysis of Factors Associated with the Incidence and Progression of Erosive Tooth Wear. Caries Research, 45, 303-312. http://dx.doi.org/10.1159/000328671

[24] Yaseen, S.M., Togo, R.A., Meer, Z., Al-Dheer, A.M., Al-Futaih, M.A., Al-Jalal, A.A. and Al-Qahtani, N.S. (2013) Dental Erosion among 12-15-Year-Old School Boys in Southern Saudi Arabia. Archives of Orofacial Sciences, 8, 1419.

[25] Aguiar, Y., dos Santos, F., Moura, E., da Costa, F., Auad, S., de Paiva, S. and Cavalcanti, A. (2014) Association between Dental Erosion and Diet in Brazilian Adolescents Aged from 15 to 19: A Population-Based Study. The Scientific World Journal, 2014, Article ID: 818167. http://dx.doi.org/10.1155/2014/818167

[26] Chrysanthakopoulos, N. (2012) Prevalence of Tooth Erosion and Associated Factors in 13-16-Year Old Adolescents in Greece. Journal of Clinical and Experimental Dentistry, 4, e160-e166. http://dx.doi.org/10.4317/jced.50802

[27] Hou, X.M., Zhang, Q., Gao, X.J. and Wang, J.S. (2005) Pilot Study of Dental Erosion and Associated Factors in University Student Volunteers. Chinese Journal of Stomatology, 40, 478-480. (In Chinese)

[28] Jensdottir, T., Arnadottir, I.B., Thorsdottir, I., Bardow, A., Gudmundsson, K. and Theodors, A. (2004) Relationship between Dental Erosion, Soft Drink Consumption, and Gastroesophageal Reflux among Icelanders. Clinical Oral Investigations, 8, 91-96. http://dx.doi.org/10.1007/s00784-003-0252-1

[29] Milosevic, A., Bardsley, P.F. and Taylor, S. (2004) Epidemiological Studies of Tooth Wear and Dental Erosion in 14-Year Old Children in North West England. Part 2: The Association of Diet and Habits. British Dental Journal, 197, 479-483. http://dx.doi.org/10.1038/sj.bdj.4811747

[30] Hasselkvist, A., Johansson, A. and Johansson, A.K. (2010) Dental Erosion and Soft Drink Consumption in Swedish Children and Adolescents and the Development of a Simplified Erosion Partial Recording System. Swedish Dental Journal, 34, 187-195.

[31] Zero, D.T. (1996) Etiology of Dental Erosion-Extrinsic Factors. European Journal of Oral Sciences, 104, 162-177. http://dx.doi.org/10.1111/j.1600-0722.1996.tb00065.x

[32] Jager, D.H., Vieira, A.M., Ruben, J. and Huysmans, M.C. (2008) Influence of Beverage Composition on the Results of Erosive Potential Measurement by Different Measurement Techniques. Caries Research, 42, 98-104. http://dx.doi.org/10.1159/000116118

[33] Davies, R., Hunter, L., Loyn, T. and Rees, J. (2008) Sour Sweets: A New Type of Erosive Challenge? British Dental Journal, 204, E3. http://dx.doi.org/10.1038/bdj.2007.1203 
[34] Søvik, J., Skudutyte-Rysstad, R., Tveit, A., Sandvik, L. and Mulic, A. (2015) Sour Sweets and Acidic Beverage Consumption Are Risk Indicators for Dental Erosion. Caries Research, 49, 243-250. http://dx.doi.org/10.1159/000371896

[35] Lussi, A., Portmann, P. and Burhop, B. (1997) Erosion on Abraded Dental Hard Tissues by Acid Lozenges: An in Situ Study. Clinical Oral Investigations, 1, 191-194. http://dx.doi.org/10.1007/s007840050032

[36] Wagoner, S.N., Marshall, T.A., Qian, F. and Wefel, J.S. (2009) In Vitro Enamel Erosion Associated with Commercially Available Original-Flavor and Sour Versions of Candies. Journal of the American Dental Association, 140, 906-913. http://dx.doi.org/10.14219/jada.archive.2009.0284

[37] Bartlett, D.W., Coward, P.Y., Nikkah, C. and Wilson, R.F. (1998) The Prevalence of Tooth Wear in a Cluster Sample of Adolescent Schoolchildren and Its Relationship with Potential Explanatory Factors. British Dental Journal, 184, 125-129. http://dx.doi.org/10.1038/sj.bdj.4809560

[38] van Rijkom, H.M., Truin, G.J., Frencken, J.E., Konig, K.G., van’t Hof, M.A., Bronkhorst, E.M. and Roeters, F.J. (2002) Prevalence, Distribution and Background Variables of Smooth-Bordered Tooth Wear in Teenagers in the Hague, The Netherlands. Caries Research, 36, 147-154. http://dx.doi.org/10.1159/000057874

[39] Smith, B.G., Bartlett, D.W. and Robb, N.D. (1997) The Prevalence, Etiology and Management of Tooth Wear in the United Kingdom. Journal of Prosthetic Dentistry, 78, 367-372. http://dx.doi.org/10.1016/S0022-3913(97)70043-X

[40] Robb, N.D., Smith, B.G. and Geidrys-Leeper, E. (1995) The Distribution of Erosion in the Dentitions of Patients with Eating Disorders. British Dental Journal, 178, 171-175. http://dx.doi.org/10.1038/sj.bdj.4808695

[41] De Bate, R. and Tedesco, L. (2006) Increasing Dentists' Capacity for Secondary Prevention of Eating Disorders: Identification of Training, Network, and Professional Contingencies. Journal of Dental Education, 70, 1066-1075.

[42] De Bate, R.D., Shuman, D. and Tedesco, L.A. (2007) Eating Disorders in the Oral Health Curriculum. Journal of Dental Education, 71, 655-663.

[43] Miller, P.M., Ravenel, M.C., Mauldin, M.P., Sulkowski, S., Lowndes, A., Thomas, B.A. and Thomas, S.E. (2014) An Online Alcohol and Oral Health Curriculum for Dental Students. Journal of Dental Education, 78, 16-23.

[44] Nadershahi, N.A., Bender, D.J., Beck, L. and Alexander, S. (2013) A Case Study on Development of an Integrated, Multidisciplinary Dental Curriculum. Journal of Dental Education, 77, 679-687.

[45] Brondani, M.A. and Rossoff, L.P. (2010) The "Hot Seat" Experience: A Multifaceted Approach to the Teaching of Ethics in a Dental Curriculum. Journal of Dental Education, 74, 1220-1229.

[46] Commission on Dental Accreditation (2010) Accreditation Standards for Dental Education Programs. Chicago. 